\title{
Chapter 20 \\ The University Unbound: How Roots and Routes Intersect
}

\author{
Jane Kenway
}

Around the world considerable numbers of students are on the move to study undergraduate and postgraduate courses in universities outside their home country. According to the Organisation for Economic Co-operation and Development (OECD), 4.5 million students studied abroad in 2012, in contrast to 4.1 million in 2010, 2.01 million in 2000, and 1.03 million in 1990 (OECD, 2014). Clearly the numbers have increased steadily over the last three decades. My main purpose in this chapter is to consider some consequences of such student mobility and the university practices associated with it. I argue that these have implications for both conventional geographical understandings of the university and for contemporary geographies of knowledge. Meusburger (2015) observes that the geography of higher education recognizes that:

The generation and diffusion of scientific knowledge is influenced by local milieus and spatial relations; that scientific practices vary from place to place; that social environments have an impact not only on generating, evaluating, and legitimizing new scientific knowledge, but also on the reading and interpretation of texts; that universities are not simply locations but social spaces, epistemic venues, and knots of scientific networks. (p. 169)

This chapter speaks to these themes and points to the complex politics that exist at the microscopic and telescopic nexus of knowledge, place, student mobility, and academic territoriality — and indeed the books we read.

\footnotetext{
Thank you to Hongzhi Zhang for producing the tables, to Hongzhi and Philip Wing Keung Chan for inviting me to be so centrally involved in the Asia as Method in Education Studies project and to all the other participants. The process was deeply educative for me. I also acknowledge that the inspiration for this chapter arose from this project and that I draw from different parts of our book, Zhang, Wing Keung Chan, and Kenway (2015). Permissions have been granted.
}

\author{
J. Kenway $(\bowtie)$ \\ Faculty of Education, Monash University, Victoria, Australia \\ e-mail: jane.kenway@monash.edu
}




\section{The Reconfigured University}

Global student mobilities, and the technologies that facilitate them, have changed the configuration of the university itself. In many ways it has become unbound. It can no longer be understood as unambiguously bounded with an obvious in and outside, with self-evident insiders and outsiders, or as having a clear-cut community. As a place it is being remade, with the links between place and institutional identity and identification being reworked.

The notion that place is socially and politically produced and contested invites a consideration of the manner in which the university is "made" or "performed" in the contemporary asymmetrical global context. The university is now a place where various expressions of globalization intersect and conflict. Indeed, as Goddard (this volume) points out, the civic university navigates globalization as it is expressed in the city. His analysis and mine here suggest that contemporary universities are involved in various new place- and scale-making projects. This involves them instigating global connections and imaginations while also attempting to remain connected to place. In geographical terms, then, the university, as an institution, now needs to be understood not just as territorial, as a place of institutional, national, and subnational roots, but also as a place of global, regional, and transnational routes.

I offer an illustration of what this reconfigured university of "routes and roots" (Clifford, 1997) looks like up close for particular sets of students and for the types of knowledge they are exposed to and seek. I show some ways that roots and routes intersect. In so doing I point to certain related "power geometries" (Massey, 1993, p. 59) and "emotional geographies" (Bondi, Davidson, \& Smith, 2005) on different scales. A myriad of microscopic realignments occur as intertwined institutional, subnational, and national cultures adjust.

Such complexity needs to be made comprehensible, and Williams (1977) is helpful here. He talks about culture involving dominant, residual, and emergent elements. Dominant elements are those that are sanctified. They need to be understood in terms of the unequal power relationships that underpin them. Emergent elements are those that are in the process of being developed. They are coming into view; they may start from the margins but are establishing a presence. They are essentially different from the dominant and arise out of new sets of social and economic conditions. They may or may not become dominant. Residual elements arise from earlier times and social formations and usually represent earlier stages in a spatial entity's biography. They tend to be subordinate. Indeed, residual elements may persist even when the conditions that initially made them powerful have passed. Dominant elements may incorporate, reinterpret, or dilute both emergent and residual elements. They may also marginalize them, particularly if they are uncomfortable and/or oppositional. When linked to roots and routes these notions speak to the dynamic and contradictory quality of today's university unbound. 


\section{Patterns of Student Mobility}

Let me offer a brief indication of the numbers associated with student mobility and draw attention to the related asymmetrical patterns of global power. The international agencies UNESCO and the OECD and the U.S.-funded Project Atlas, among others, statistically document mobile students' movements over time, place, and institution. The involved researchers show how and where the numbers rise and fall and speculate about why. The data records such things as the total numbers globally, regionally, and nationally. For example, UNESCO documents the main countries that students travel to (see Table 20.1) and depart from (see Table 20.2). Invariably national comparisons are made. For example, in Australia and the United Kingdom international students comprised $20 \%$ of total higher education enrollment in 2014. In comparison, the proportion in France and Canada was 12\%, in Germany 11\%, in the United States and Japan 4\%, and in China 1\% (Project Atlas, 2014). In comparison, for France and Canada the proportion was $12 \%$, for Germany $11 \%$, for the United States and Japan 4\%, and for China 1\% (Project Atlas, 2014).

Regional comparisons are also drawn. UNESCO (2015) shows that in 2012 the regions hosting the most mobile students were "North America and Western Europe (57\% of total mobile students), East Asia and the Pacific (20\%), Central and Eastern Europe (10\%)." UNESCO also points out, however, that increasingly the rise of regional hubs has led to a shift in such region flows. The agency says, for example, "Australia and Japan, traditional destinations in East Asia and the Pacific, are rivaled by newcomers China, Malaysia, the Republic of Korea, Singapore and New Zealand, which hosted $6 \%$ of the global share of mobile students in 2012" (UNESCO, 2015). The global, regional, and national picture of flows is both patterned and fluid. Exit and entry numbers go up and down, locations fluctuate somewhat in popularity, new patterns emerge, and older patterns adjust, but, to date, remain dominant.

National reporting agencies, Australian in the examples used here, focus on such things as total numbers and income. The number of overseas students in Australia was 249,990 in $2014,225,720$ in 2009, and 164,044 in 2004. For 2014-2015 income generated by their presence in Australia was AU\$18.1 billion (Universities Australia, 2014). Such agencies also focus on student load by university (see Table 20.3), overseas students by country of birth and gender (see Table 20.4), and, of course, a wide array of other matters.

Such matters include what is often called transnational education. This involves offshore programs delivered in partnership with an international institution or through offshore national university campuses. As Universities Australia (2014) points out it also involves "formal institution-to-institution agreements between Australian universities and overseas higher education institutions. Agreements include cooperation facilitating student exchanges, study abroad arrangements, staff exchanges and academic/research collaboration" (p. 21).

Regions, countries, and institutions have their own distinctive histories of flows. For instance, student mobility in Europe has been significantly boosted as result of 


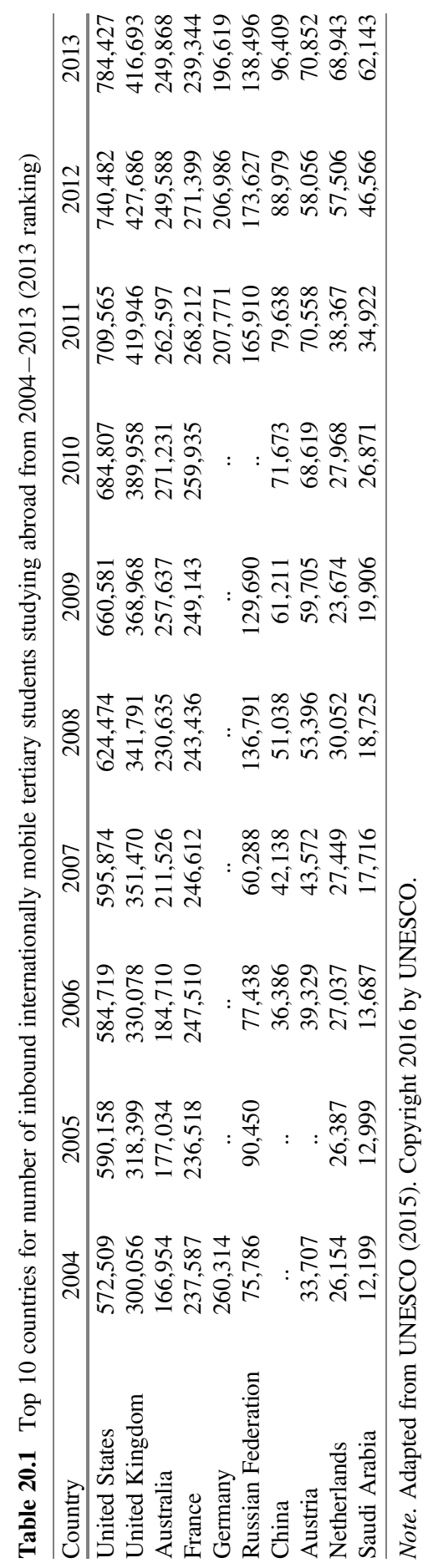




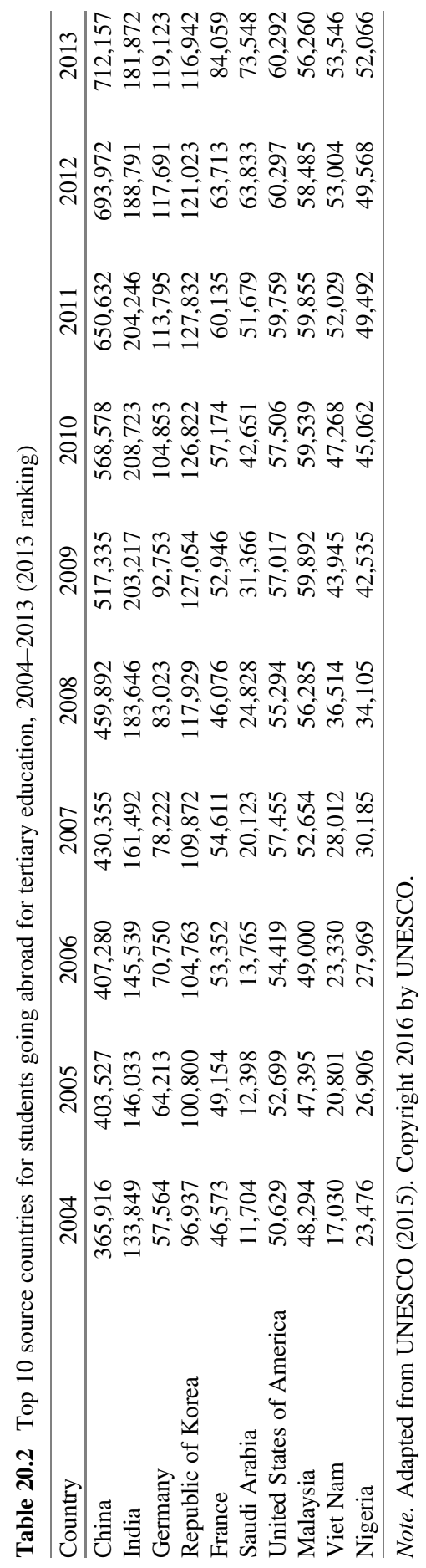


Table 20.3 Equivalent full-time student load (EFSL) for commencing and all overseas students by higher education institution and gender, 2014

\begin{tabular}{lcccccrrr}
\hline & \multicolumn{3}{c}{ Commencing Enrollment } & & \multicolumn{3}{c}{ Total Enrollment } \\
\cline { 2 - 3 } & Males & Females & EFSL & & Males & Females & EFSL \\
\hline RMIT University & 3,926 & 3,702 & 7,629 & & 10,270 & 9,772 & 20,043 \\
Monash University & 3,587 & 4,272 & 7,859 & & 9,355 & 10,278 & 19,634 \\
University of Melbourne & 2,533 & 3,197 & 5,729 & & 5,835 & 7,365 & 13,200 \\
Curtin University of Technology & 2,275 & 2,137 & 4,412 & & 6,041 & 5,505 & 11,546 \\
University of Sydney & 2,120 & 2,980 & 5,100 & & 4,646 & 6,332 & 10,978 \\
University of New South Wales & 2,384 & 2,293 & 4,677 & & 5,771 & 4,834 & 10,605 \\
University of Queensland & 1,779 & 2,359 & 4,138 & & 4,417 & 5,386 & 9,802 \\
Non-University Higher Education & 3,507 & 2,163 & 5,670 & & 5,977 & 3,619 & 9,596 \\
Institutions & & & & & & \\
University of Wollongong & 2,048 & 1,470 & 3,519 & & 5,343 & 3,867 & 9,210 \\
Non-University Higher Education & 2,785 & 2,424 & 5,210 & & 4,878 & 4,203 & 9,081 \\
Institutions & & & & & & \\
\hline
\end{tabular}

Note. Adapted from Australian Government (2014). Copyright 2016 by Department of Education and Training. EFSL $=$ Equivalent full-time student load (EFSL) is a measure of a student's study load. An EFSL of 1.0 is the standard annual study load of a student undertaking a program on a fulltime basis. Equivalent full-time student load (EFSL) is a measure of a student's study load. An EFSL of 1.0 is the standard annual study load of a student undertaking a program on a full-time basis.

Table 20.4 Overseas students by country of birth and gender, 2014

\begin{tabular}{lccc}
\hline Country of Birth & Male & Female & Total \\
\hline China (excludes SARs and Taiwan) & 45,825 & 54,175 & 100,000 \\
Malaysia & 14,525 & 14,543 & 29,068 \\
Singapore & 13,073 & 15,194 & 28,267 \\
India & 18,143 & 7,875 & 26,018 \\
Viet Nam & 8,809 & 10,052 & 18,861 \\
Hong Kong (SAR of China) & 6,727 & 5,754 & 12,481 \\
Indonesia & 5,992 & 5,762 & 11,754 \\
Nepal & 5,272 & 3,310 & 8,582 \\
Republic of South Korea & 3,255 & 3,253 & 6,508 \\
United States & 2,528 & 3,926 & 6,454 \\
Total & 180,602 & 166,958 & 347,560 \\
Total 2013 & 168,089 & 160,313 & 328,402 \\
\% change from 2013 & 7.4 & 4.1 & 5.8 \\
\hline
\end{tabular}

Note. SAR $=$ special administrative area. Adapted from Australian Government (2014). Copyright 2016 by Department of Education and Training.

the Erasmus Program and the Bologna Process in higher education. The European Commission regards such mobility as one way to integrate the European region. Australia is distinctively tied to Asia, but the Asian Region has no imperatives similar to Europe. 
Although certain policy bodies and institutes mention the quality of the education offered and the advantages to the parties involved, the primary concern is invariably the trade in education services, competition, and market share. Typically the OECD points to the individual, social, and cultural benefits but appears to give greater priority to economics. It says: "Studying abroad has considerable economic impact. For host countries enrolling international students can not only help raise revenues for higher education, but also can be part of broader strategy to recruit highly skilled immigrants" (OECD, 2014, p. 32). The following remark from Universities Australia (2014) is also typical.
An international education contributes to the development of global citizens, regional leaders and strong global relationships that are so critical for facilitating diplomacy, business and trade. This is the case whether it is overseas students studying in Australia or Australian students completing at least part of their degree overseas. There is great potential to further expand the international reach of the Australian university sector. With global demand for higher education set to grow significantly in coming decades, even maintaining or margin- ally increasing Australia's market share could deliver major export growth. ${ }^{1}$

Such policy-oriented comments about the benefits rarely involve a close-up examination of what actually happens to students on the ground. I will return to this matter. But despite such intense coverage, insufficient attention is drawn to the asymmetrical patterns of power and wealth connected with such student mobility. In contrast, UNESCO's 2012 Global Flow of Tertiary-Level Students interactive map enables such an understanding of student flows in relation to the rich and poor nations of the global South and North, West and East. For example, it points out that

the Arab states of Egypt and the United Arab Emirates (Dubai) are popular destinations for high-level studies for Arab students, and South Africa received 17\% of mobile students from Sub-Saharan Africa in 2010.

France remains the top destination for Arab and Sub-Saharan African students, receiving $29 \%$ and $19 \%$ of these students respectively. Germany and Russia are the top destinations for students from Central and Eastern Europe, and Central Asia, receiving 16\% and 46\% of these regions' students respectively.

The US is the top destination for East Asia and the Pacific, South and West Asia, and Latin America and the Caribbean, receiving 28\%, 38\% and 33\% respectively of their mobile students. And North America and Western Europe's top destination is the UK at $23 \%$. (UNESCO, 2015)

Such figures indicate that these flows of students are primarily from the "third" world to the "first" or, what is better referred to as the majority and minority worlds. But interestingly and most importantly for this chapter, these student flows are often either from formerly colonized countries to former colonizing countries, or to the globally imperialist power of the United States with its Cold War history in Asia, and to these countries' satellites. As Table 20.4 shows for Australia, for example, nine of the top ten sending countries are from different parts of Asia.

As some governments in the magnet countries reduce their financial support for university education, the global market in tertiary education has stepped into the

\footnotetext{
${ }^{1}$ https://www.universitiesaustralia.edu.au/global-engagement.
} 
vacuum. Mobile students' fees now increasingly underwrite the survival of their university sector and thus students from poorer countries help to underwrite university education systems in the richer countries. This is a contemporary echo of colonialism.

This echo resonates even more strongly when the flows of knowledge are taken into account. These too are usually from the global North to the global South (e.g., Chakrabarty, 2000; Connell, 2007). Plainly, the current global university system has its own "geographies of centrality and marginality" (Sassen, 1998, p. XXIV), its own integrating and fragmenting tendencies.

Transnational education complicates such geographies. Offshore campuses allow students to study "abroad" while remaining in their home countries. Mixed modes of study, which combine online and face-to-face teaching, may involve no, or little, physical presence on the campus of origin. This virtual and embodied mobility of people (students, staff) and knowledge (curriculum and research) is accompanied by other mobility - the mobility of ideologies, images, and imaginations; of finance, feelings, and fantasies. Such mobilities have been facilitated by the space-and-timealtering technologies of cheap transport and instantaneous information communication technologies. Hence university relationships that would otherwise have been stretched out over extended literal space have been both compressed and reconfigured with great consequence for the geography of the university.

\section{The Unequal Geographies of Traveling Ideas}

The following case is but one example of the complicated intersections of roots and routes in the contemporary university. It shows how they are entangled with dominant, residual, and emergent elements in relation to various spatial entities.

I begin with a book as it traveled to the hands, hearts, and minds of a group of doctoral students at Monash University, Australia. As Table 20.3 indicates, Monash had the second highest number of international students of any Australian university, with enrollment of 19,634 in 2014. All the doctoral students involved in the project were from Asia and as a result of this book sought to decolonize knowledge and themselves. In telling their story I foreground the dominant, residual, and emergent power, knowledge, and emotional geographies involved. While the notion of emotional geographies is widely evoked in geographical studies, the emotional geographies of education, particularly of universities, have attracted much less attention (Kenway \& Youdell, 2011a, b) ${ }^{2}$.

The book is called Asia as Method: Toward Deimperialization (Chen, 2010). It was written by Kuan-Hsing Chen, a well recognized cultural studies scholar. I found it in Singapore, and given that Australia generally, and Monash specifically, draws

\footnotetext{
${ }^{2}$ Our edited collection (Kenway \& Youdell, 2011) is dedicated to the emotional geographies of various educational settings.
} 
most international students from Asia, I took it back to Monash's Faculty of Education for a graduate student reading group. It provoked a great deal of interest from the students. This resulted in a multicountry reading, discussion and reflection, writing, and public presentations project that lasted several years (2010-2013) and eventually led to the edited book Asia as Method in Education Studies (Zhang, Wing Keung Chan, \& Kenway, 2015), in which the students wrote chapters and, after each, shared their reflections on their experiences of trying to decolonize knowledge.

In 2010, when the project started, in total 34 people were involved; 7 academics and $20 \mathrm{PhD}$ students. Also there were 10 observers who did not join the project but attended some seminars and workshops. Those involved were from 13 countries-Australia, Bangladesh, China, Indonesia, Iran, Malaysia, Mongolia, Pakistan, New Zealand, Saudi Arabs, Sri Lanka, Thailand, and Vietnam. Many different religions and native languages were represented in the group, with the students coming from different social class backgrounds. Twenty-two students were involved in the final book. They came from Australia, Bangladesh, China (including mainland and Hong Kong), Indonesia, Japan, and Vietnam.

Collectively the project involved people connected to 13 other universities. Many were staff on leave undertaking their PhDs who planned to return to their universities once they had completed their doctorates. These universities were the University of Hong Kong, Monash University, Swinburne University of Technology, Australia, RMIT University Vietnam, Universidad de Valparaíso Chile, Sanata Dharma University Indonesia, Indonesia University of Education Indonesia, State Polytechnic of Malang Indonesia, Hanoi National University of Education Vietnam, Hanoi University of Languages and International Studies Vietnam, University of Dhaka Bangladesh, BRAC University Bangladesh, and the University of Western Sydney, Australia.

These details alone indicate some ways Monash, at least, is a place of flows; one at which different people's Asian routes intersect. But more interestingly it is also a place where geographies of knowledge, power, and emotion are entangled with regard to Asia. Chen's book starts to explain the geopolitics involved. The West, he says, has understood and portrayed itself, to itself and to "the rest," as "the best." It has presented itself as the most modern, mature, developed, progressive, scientific, rational, enlightened, and civilized. Such views traveled to colonized countries and peoples and impacted how they felt about themselves as well as about their colonizers. Consequently, knowledge production in Asia, Chen (2010) argues, is constantly either positively or negatively referencing the West. It has been an opposing entity, a system of reference, an object from which to learn, a point of measurement, a goal to catch up with, an intimate enemy, and sometimes an alibi for serious discussion and action (p. 216). He makes similar arguments about the conceptual frameworks that arose out of the Cold War and are connected to North American imperialism in Asia.

Previous and current generations of postcolonial scholars have, of course, been critical of this. Chen identifies various types of postcolonial response. For example, one body of such scholarship identifies and challenges Eurocentric and/or North America-centric thinking, by, among other things, highlighting the binary and 
hierarchical logics deployed when the West constructs its Others. These logics, the argument runs, create global hierarchies of knowledge and modernity. They also involve implicit claims that "Western" knowledge is universal, when in fact it is provincial or regional. Such postcolonial critiques ask, rhetorically, whether the analytical frameworks that have been developed in Europe or North America are suitable for understanding Asia. And they are highly critical of the ready absorption of such frameworks into research about, on, and in Asia.

According to Chen, new scholarship in Asia needs to be in a dialogue with such postcolonial responses to the West. He also insists, however, that from an "Asia as Method" perspective, certain postcolonial studies should stop the West as their primary referent $(2010$, p. 222). Otherwise, he says, they may contribute to the use of new unhelpful binary reversals, the "East is best" for example. Problems also occur around three other approaches to knowledge that may arise in newly independent nations in their attempts to shake off the shackles of the colonizer. Chen names these as nationalism, nativism (notions of ancient wisdoms, for example), and civilizationism (competing claims about whose civilization is the more civilized).

Overall, Chen pleads for habitual practices of thought to change. He argues for "alternative mappings" that move "the point of reference" (2010, p. 212). An essential ingredient is to shift this point of reference toward Asia and other third world locations - to those places with greater resemblances to each other, to those that share and address similar problems. This point leads him to emphasize Asian studies in Asia, as opposed to Asian studies through European and North American theorizing about Asia. Such theories do not usually, he claims, help people in Asia to properly understand or address local conditions or issues.

He proposes, instead, "international localism" (p. 223). This is local, but also transborder and regional. The main point though is that it involves "interreferencing" (p. 223). Here Asian countries become each other's reference point; they provide each other with new opportunities for comparison other than the constant comparison with the West. The purpose of the inter-referencing approach is to avoid judging any country, region, or culture as superior or inferior to any other and to tease out historical transformations within the base entity of each country so that the differences can be properly explained (p. 250). New intellectual alliances and solidarities need to be built, Chen claims.

In terms of emotional geographies and their implications for knowledge, Chen focuses on three things: structures of sentiment, the psyche, and subjectivity (p. 74). He draws from postcolonial psychoanalytic theory to help explain various paradoxes. First, Chen explains the psychology of colonization from the perspective of the colonizer. For instance, this way of thinking includes the practice of regarding people in the colonies as at an immature stage of development and, thus, as needing guidance from the colonizing country to enable them to reach maturity (p. 74). Secondly, against such deficit thinking alternative postcolonial analytics arose and existing psychoanalytic theory was rewritten in support of decolonizing movements. These analyses were regarded as a "weapon in the anti-colonial struggle" (p. 74). Such postcolonial theorists sought to analyze the psychology of the colonized and pointed to such things as colonial identification, the unconscious yearning (desire) 
for the colonizer's recognition, and the accompanying psychic suffering and resentment (p. 78). They focused, too, on the manner in which colonizer and colonized constitute each other's subjectivity. And, they examined the psychology of decolonization and national independence, pointing to the unfortunate continuation of earlier subjectivities (pp. 78-79).

One methodological implication of this line of analysis is that the researcher's subjectivity and identifications must come under scrutiny. Not least, the research community's "structural flow of desire" (Chen, 2010, p. 225) towards the United States and Europe needs to be challenged. Chen calls for a ruthless self-questioning, a process of self-critique, self-negation, and self-rediscovery (p. 3). Alternative cultural practices of identification are required. In the first instance, this involves acknowledging that the psyche may still be framed in such deleterious ways and that moving beyond the limits of such framings is crucial.

\section{Dominant and Emergent Institutional and National Roots}

Chen's ideas traveled to Australia though the work of the students. I explain how and also deploy his ideas to analyze the students' responses, and in so doing ask if, and how, his work on the geopolitics of knowledge spoke to the students and their situation. But also, as I have indicated, in the contemporary university global routes invariably meet institutional and national roots. So I also explore the character of the dominant, residual, and emergent roots the students encountered and their implications for these mobile $\mathrm{PhD}$ students and moving ideas.

First, to a consideration of some dominant roots: Universities potentially constrain international students' engagements in the geopolitics of knowledge through time, money, and language. These students paid exorbitant fees, and felt an intense pressure to complete on time. Additional time pressure was often due to scholarship and visa requirements. For those seeking work and/or permanent resident status in Australia more intensity arose. The requirement to write and talk in the English language was very demanding and required high levels of linguistic and cultural translation. While these did not prevent students' engagement with Chen's ideas, they did impinge on it.

The manner in which these students' identities and research imaginations were constructed at Monash, during their time there, was deeply rooted in a residual colonial imagination. Practices of infantalization and deficit models were subtly present. First, the knowledge the students brought with them was often downplayed or ignored, thus involving a denial of their full selfhood. Secondly, they were not usually encouraged to use research sources from their own countries or region, especially those not written in English. Thirdly, they were usually steered toward the knowledge and theory that their supervisors were most familiar with. This was almost inevitably knowledge from what might be called empires of English-language-knowledge-particularly the United States or the United Kingdom. Such knowledge has long been sanctified in this education faculty. 
The students brought with them national attachments that, in some instances, intensified during their overseas studies as they struggled for self-differentiation in the Faculty (Chen, 2010, p. 87). They did not necessarily have an unconscious yearning (desire) for the knowledge colonizer's recognition as might their forebears. But in some ways the academic culture into which they came required of them some forms of self-negation and mimicry. To adopt this pose become a strategic choice of survival and progress for some.

Postcolonial psychoanalytic theory makes it clear that imperial centers and colonies were mutually constituted. Each shaped the other. For the colony to be constituted as inferior, the center has to constitute itself as superior. Such sentiments linger. Plainly, the students and the institution constituted each other's subjectivity in asymmetrical ways.

Chen draws attention to the importance of deimperializing knowledge and this call is directed toward those at the centers of empires of knowledge. These are the peoples who most benefit from Eurocentric and North America-centric epistemologies and ontologies. Thus an important ingredient of Asia as Method is the deimperialization of knowledge by those who are or have been imperial powers in different parts of Asia. This includes England, France, the Netherlands, Portugal, Spain, and the United States. It also includes those countries within Asia that have been colonizers as well as colonized. Chen (2010) says that deimperializing research starts with rethinking the wrongs and pains of past imperialist interventions.

This must be performed by the colonizer first and then on the colonizers' relation with its former colonies. The task is for the colonizing or imperializing population to examine the conduct, motives, desires and consequences of imperialist history that has formed its own subjectivity. (p. 4)

The students were mindful of Chen's arguments about the importance of deimperializing knowledge. And, in terms of education studies they found succor in Lin's (2012) assertion that "Knowledge production (e.g., textbook/curriculum production, university research and publication, teacher preparation) and knowledge circulation (e.g. schooling, curriculum, and pedagogy) constitute the major sites in which imperialism operates and exercises its power" (p. 164).

Clearly, according to this logic, those living and working at the centers of various empires of knowledge must move beyond what Hall calls "the West as Method" (1992). This meant that the students' non-Asian academic colleagues in the education faculty needed to engage with the sorts of issues they were raising and attend to the emergent knowledge they were working with. The students did not subscribe to the hard-to-justify essentialism that leads to the view that only Asians can do Asia as Method and that white, non-Asian scholars should be excluded. Their view was that such scholars should be seriously involved in order to deimperialize their own supervision practices as well as their own scholarly enquiries. They thus invited others in the faculty to join this project.

But within the wider faculty little such deimperializaton occurred. The dominant roots mentioned above were too deeply entrenched. Few members of academic staff became involved and explored, with students, the implications of Asia as Method for 
curriculum and educational inquiry and practice, let alone for their post graduate pedagogies. More widely, at conferences and seminars it was mostly Asian staff and students who attended students' papers and symposia. The education main stream seemed to remain pretty much untouched and unchanged.

That said, emergent potentially decolonizing knowledges were available. Some $\mathrm{PhD}$ supervisors encouraged their students to engage with postcolonial theory, with debates about the geopolitics of globalization and the implications for education. Some also encouraged them to draw on the research and theorizing of scholars from their home country and region. However that was relatively rare.

Of course all international students are subject to their host country's policies and practices with regard to them. Australia has been in the "industry" since the 1980s, so these policy roots are well established and overriding. Australia's higher education system is dependent on international students from Asia, so it has high policy priority. But also emergent elements in relation to Asia came from Australia's national polity during the time of the project, ones that might have been expected to elevate the students' institutional status.

These involved the Australian national government's attempts to reimagine its relationships with Asia. At the time, Asia was strongly on the agenda in Australian political circles and Australia was thinking hard about its place in the Asian region. Australia is geographically located in Asia but it is not of Asia. It is a wealthy, "first" world country surrounded by many countries that are considered "third world." It has strong historical links with Britain and the Commonwealth of Nations but its political and military alignments are, primarily, with the United States and Europe. That said, Australia is, as Takayama (2016, p. 70) points out, a "rich peripheral country" plagued by a sense of ambivalence about its own identity internally and on the world and regional stages (see, further, Kenway \& Fahey, 2011).

Australia has strong trade links with South Korea, Japan, and, particularly, China and India. And, it is because of the increasing dependency of Australia on these trade links that it has become much more conscious of its need to better attend to its Asian neighbors. This impulse is signaled in the policy document Australia in the Asian Century (Australian Government, 2012) that says:

The Asian century is an Australian opportunity. As the global centre of gravity shifts to our region, the tyranny of distance is being replaced by the prospects of proximity. Australia is located in the right place at the right time-in the Asian region in the Asian century. (p. 1)

And, in terms of school education, the Australian Curriculum named "Asia and Australia's engagement with Asia" as one of only three cross-curriculum priorities (Australian Curriculum Assessment and Reporting Authority, 2014). It seeks to ensure that Australian students learn about and recognize the diversity within and among the countries in the Asian region. It, also, aims to develop students' knowledge and understanding of Asian societies, cultures, beliefs, and environments and the connections between the peoples of Asia, Australia, and the rest of the world.

Chen notes that capital's globalization has led to "economic and cultural regionalization" and along with this has come "the rise of Asia as a pervasive structure of sentiment" (2010, p. 214). It might be added however, as Rizvi (2012) notes, the not- 
too-subtle subtext to such policy mantra is usually instrumental and economically opportunistic. Understanding Asia in the manner Chen proposed, as a shifting historical, political, cultural, as well as economic entity, was not what this was about.

But even though Asia was strongly on the agenda in Australian political and national curriculum circles at the time and even though the time seemed ripe for deimperializing knowledge in the faculty, the institutional roots attached to empires of English-language-knowledge were too deep.

\section{Routes that Settle and Unsettle}

The graduate students traveled to Australia with much highly contradictory, even split, emotional baggage. This was not just about the "flow of desire" to the West, according to Asia as Method; although as one of my former graduate students made clear in her doctoral thesis (Nguyen, 2013), students in Asia are sold "Western dreams" via the intense marketing practices of Australian universities in Asia.

Most of the graduate students from Asia tended to focus their research on educational issues in their home country, yet were usually encouraged to draw on Western perspectives to study their own country's educational practices and systems. They often, therefore, utilized Western concepts and theories to interpret the issues involved. The emotional geographies involved were complicated.

Some appeared to readily accept this situation and were eager for knowledge from the West. Others were uneasy. Of the uneasy some saw this as under-valuing Asian intellectual traditions and practices and as unsuitable for Asian circumstances. Their typical counter-response was to turn to their local knowledge to interpret local educational issues in their home country. My conversations with them concerned the dilemmas they faced about the relationships between knowledge and location, universalism and specificity. Yet others found it quite difficult to specify why they felt uncomfortable - they just did.

The students' Asian-ness was affirmed through the project. International students who come from "other/othered" countries often develop affinities across nation states that they may not otherwise feel. And the project contributed to such new communities of affect, to new solidarities. The following remarks from our group's final reflective session illustrate the point.

For me, the way I perceive myself in a different context is slightly different. I don't perceive myself as Vietnamese, but I perceive myself in the broader spectrum with other Asians. When I was in the United States, I didn't think of myself as Vietnamese, I thought of myself as Asian. So when I see a Chinese, I feel close to the Chinese person. When I'm in Vietnam, if a Chinese person came and visited, I would think, "He's so different."

When you're somewhere else, you tend to draw on who you're not. So for example, back home, I never think of myself as Indonesian-Muslim. That's something you take for granted. But here, it's like the religion is being foregrounded and my skin colour as well.

As an international student away from home ... you may not find a lot of international students from the same country in the same subject, in the same faculty, so you just think, "It's a student from an Asian country, we can form a community so we support each other. 
But the project also exemplified some of the knowledge problems that Chen identifies. Early on, the students organized themselves into small subgroups to develop papers for a half-day faculty seminar. The groups were all nation-state based. They later presented papers at national peer-refereed conferences. The feedback required them to deepen their understandings of Chen and they then began to undertake the ruthless self-questioning, and process of self-critique, self-negation, and self-rediscovery that Chen calls for. This was necessary but difficult intellectual and psychic work. The reasons were manifold.

As time went on, there was some worry around the politics of the project. Various concerns surfaced about the publication and what it might mean politically when students returned home. It is not uncommon for students who become politicized in certain ways in the West to face the prospect that such politics may not be welcome at home. But these anxieties were not just about the possible problems of return.

They were also concerned about disciplinary territories and borders, about, for example, whether ideas from cultural studies should travel into education studieswere they too political, were they useful for teachers, they asked. For such students the project unsettled firmly installed and held disciplinary identities. They sought to reconfigure their own intellectual horizons and to try to reimagine the discipline of education and its methodologies. They came to acknowledge, for instance, that the discipline of education is not simply apolitical and practical. But they also raised for discussion the many problems of translation across disciplines and political standpoints.

Of knowledge and decolonization the project did not do as much as Chen would have liked. The papers for the book did not do the necessary "inter-referencing" (p. 223) that Chen (2010) calls for. But some spatial unsettling occurred. At the project's start, the students were quite ignorant about each other's countries. But they developed a curiosity where little was there before. They wanted to know more. This shifted their points of reference to some extent and, in this sense, the project was a space of emergence wherein routes challenged roots.

The project raised question about the geopolitics of students own knowledge horizons. It led them to ask why they knew so much about some countries in Asia and so little about others or why was it that some issues had prominence and others did not? Why, for example, was religion always in the forefront with regard to Indonesia? This led some to the view that Chen did not actually go far enough with regard to certain issues, such as the power of religion and its implications for knowledge. As Roshid, Siddique, Sarkar, Mojumder, and Begum (2015) said in the reflective section of their chapter:

\footnotetext{
Chen emphasizes freeing our minds from the influence of colonization, imperialization, and Cold War as they are deeply rooted in many Asian contexts, eventually posing challenges for Asian scholars when they move forward in knowledge generation. In the context of Bangladesh, we would argue for considering other aspects to liberate our minds and move forward. In particular, the influence of religious ideology plays a vital part in shaping people's mindset. For example, a considerable part of the population neither accepts Western knowledge nor tries to generate local knowledge. Instead, it relies on Islamic knowledge and continues a solely Islam-based education system in Bangladesh, adding another dimension to Chen's critique. (2010, pp. 141-142)
} 
All that said, throughout the students held strong, spatially organized knowledge disposition and in many ways continued to think through the prism of the nation state. Chen claims that "if critiques remain within the limits of the nationalist framework, it will not be possible to work towards regional reconciliation" (2010, p. 159). As indicated, he points to the importance of affect (feeling) when it comes to the national, the colonial, and the postcolonial and to the fact that the affective investments and attachments of all three need to be acknowledged.

To understand the moods suffusing a nation-state, it is necessary to have a comprehension of its global situated-ness currently and over time. For instance, being positioned as tangential in global power formations has the potential to negatively impact the national self-image and mood. So too can the historical conditions of a nation-state, particularly if it has been on the receiving end of colonization and imperialism. These links became manifest in the collective national character and consciousness and in the national unconscious and can result in what is sometimes called a "colonial mentality," which may also involve a dependant culture. The emotional archive of the nation-state then, includes a collection of feelings and susceptibilities stored over time in both the body politic and the national culture. It includes the nation-state's underlying desires and defenses.

There were many barriers to undertaking the type of transnational imagining proposed by Chen. But nationalism was a major barrier. Nationalism and its affective registers remained an issue as our reflection sessions made clear. As one student explained, when inviting us to talk about

the nation as the basic defining unit. How come we know that it's problematic, but we always come back to it? How do we escape from this idea? We know it's very problematic and lots of stereotyping and prejudice stems from it, essentialism and all such negative connotations are attached to it. But it's just hard to escape from the notion of taking national entity as the basic defining unit. How do we deal with this?

Making one of their aspirations clear, it was proclaimed, "We need to change this. We can't move on if we don't, if we keep doing things with the same mindset as we had yesterday". But changing was difficult. The politics of knowledge is transnational, regional, national, and subnational. These politics intersect and are hard to untangle.

Students recounted stories, not just of Western colonialism and American imperialism, but also of wars and international tensions within Asia itself. Some arose from a history of war and intra-Asian colonialism. Within Asia, the major powers of China and Japan have been involved in various colonizing projects. Even less powerful countries have had their own imperial fantasies, seeking to move from being colonized to become neo-colonialists. Such national tensions led to some strains within the group. Raw emotions were exposed. For example, we discussed the tense relationships within Indonesia in relation to West Papua. Chen's idea that we could rise above such rifts though reflections, conversations, and dialogues was seen as, simply, too utopian. Even so, there were glimmers here of what Chen calls "Asian studies in Asia" (2010, p. 2). 
We also pondered those rivalries between Asians that do not seem to be connected to the matters Chen raised. "Why is it that Asians felt more threatened by other Asians, than by Western influences?" one person wondered. Another put is more colorfully, "Why are we so allergic to other Asians?" saying "When I think back to when I was a student, as a Vietnamese scholar, I didn't quote Chinese scholars. And Chinese scholars, in the same class, didn't quote Japanese. We all quoted Western people". For example, the question was raised: Why are mainland Chinese regarded by Singaporeans as more of a danger than the West?

I think we are threatened by fellow Asians more than by the West. I just came back from Singapore and that sentiment is everywhere in Singapore. . . . European culture pervades every aspect of culture there, theatre, architecture, everyday conversation, Starbucks and everything, and people just don't care. All of a sudden, a few Chinese brands came in, "What is this brand? I don't like that.

But the tensions can also be on a much more personal scale, as the following comment indicates:

Suppose I work with you for a long time and I listen to you a lot, and I have no problem. ... And one day Philip is better than me, he's published more, he gets a rise in salary. I'm threatened. Why? . . I I feel threatened because he's so similar to me, he's yellow, he's male, he's studying in the West, he's so similar. Suddenly, one day he's being valued by the system and I feel threatened.

Interestingly it was the emotional geographies involved that led to these various practices of "inter-referencing" and "international localism" in Chen's terms (2010, p. 223).

\section{Concluding Thoughts}

Now back to the contemporary university as a place of roots and routes. Admittedly this chapter has a particularity to it, as it's only one small project in one university, in a rich country that is a British and U.S. satellite. But it offers an example of the manner in which the flows of people, knowledge, and emotion intersect. It shows how such flows can come up against the dominant roots of the grounded university itself and those nation-bound roots that exist in the students' psyches. And it illustrates how power and knowledge relationships can be implicated.

More abstractly, I have suggested some benefits of bringing Chen's theorizing to studies of global flows in the contemporary university in Australia in relation to its mobile students from Asia. And I surmise that his approach could be usefully deployed in other locations in Asia and in the universities around the world to which Asian students travel. Chen not only highlights the links between colonial, postcolonial, and imperialist history and geography, power, and knowledge, but also claims that that these links live on in certain ways. I have offered an example of how they live on not just in the directions of student movement but also in the direction of knowledge flows. 
Chen's framework, with the assistance of Williams's (1977) cultural categories, provide a way of interpreting the knowledge politics of the territorial university into which Asian students travel and within which they temporarily settle. It helps to explain why they are implicitly constructed as deficit by a "Western" university. I have intimated that this is probably because a residual element in such universities involves colonial and racist views of students from Asia. And, in turn, this helps to explain at least some of the barriers that arose in relation to the emergent knowledges, which the students sought to engage. Along with the time, money, and language issues they and many international students face, such elements make the deimperialization of knowledge difficult.

Notions about the mutual constitution of colonizer and colonized are also helpful in unpacking the relationships between students from former colonies in countries that have a history of colonization, even if by association, as in the case of Australia, a former colony of the British Empire, but one with an enduring sense of its British connections. Through this notion it is possible to see the ways in which the mobile students" "desire" for a Western education and recognition potentially confirms the knowledge rooted in the dominant power relations of the university and the global university system. Equally, the argument that certain versions of postcolonialism may inadvertently confirm the colonial script provides a further explanation of the knowledge problems students might face. This happens if they try to challenge the knowledge politics of their host university by the most obvious route of binary reversal-the "East" is best.

But this study also points to some limitations of Chen's mode of analysis. One example is its restricted reading of the emotional geographies of the encounter, along the resentment or desire spectrum, and in relation to recognition though mimicry. As these students unpacked their emotional baggage it became clear that their emotional investments were more nuanced and also arose from such things as disciplinary territoriality, a rather defensive nationalism, and an emergent comparative national, not so much international, sensibility. This defensive nationalism was aimed less against the so-called West than at other forces in Asia itself. Such nationalism is a force for stasis in this space of flows, one that makes the forging of new intellectual alliances and solidarities through an Asia as Method approach improbable, but not impossible.

Finally, to suggest, as I have, that the contemporary university is unbound is not to suggest it is without roots. As indicated, in this one university at least, dominant and residual knowledge can be so deeply rooted in the institution that it in inhospitable to the emergent knowledges that flow in-particularly those knowledges that are subversive and oppositional. The existing power geometries can actually harden even when the university and the country are involved in a range of activities designed to attract and cater to international students. In short, the unbound university may also, in certain ways, be rather root-bound. 


\section{References}

Australian Curriculum Assessment and Reporting Authority. (2014). The Australian curriculum. (ver. 7.5). Retrieved from www.australiancurriculum.edu.au/

Australian Government. (2012). Australia in the Asian century: White paper. Canberra: Australian Government Publishing Service.

Australian Government. (2014). Selected higher education statistics-2014 student data. In Australian government: Department of education and training. Retrieved from https://education. gov.au/selected-higher-education-statistics-2014-student-data

Australian Government Department of Education and Training. (n.d.). International student data. In Data and Research (section 5). Retrieved from https://internationaleducation.gov.au/research/ International-Student-Data/Pages/default.aspx

Bondi, L., Davidson, J., \& Smith, M. (2005). Introduction: Geography's 'emotional turn'. In J. Davidson, M. Smith, \& L. Bondi (Eds.), Emotional geographies (pp. 1-19). Ashgate: Aldershot.

Chakrabarty, D. (2000). Provincializing Europe: Postcolonial thought and historical difference. Princeton: Princeton University Press.

Chen, K.-H. (2010). Asia as method: Toward deimperialization. Durham: Duke University Press.

Clifford, J. (1997). Routes: Travel and translation in the late twentieth century. Cambridge, MA: Harvard University Press.

Connell, R. W. (2007). Southern theory: The global dynamics of knowledge in the social sciences. Sydney: Allen and Unwin.

Hall, S. (1992). The West and the rest: Discourse and power. In S. Hall \& B. Gieben (Eds.), Formations of modernity (pp. 275-332). Cambridge, UK: Polity.

Kenway, J., \& Fahey, J. (2011). Getting emotional about 'brain mobility'. Emotion, Space and Society, 4, 187-194. doi:https://doi.org/10.1016/j.emospa.2010.07.003

Kenway, J., \& Youdell, D. (2011). The emotional geographies of education: Beginning a conversation. Emotional geographies of education [special issue]. Emotion, space and society, 4, 131-136. doi:https://doi.org/10.1016/j.emospa.2011.07.001

Kenway, J., \& Youdell, D. (Eds.) (2011b). The emotional geographies of education [Special issue]. Emotion, space and society, 4.

Lin, A. M. Y. (2012). Towards transformation of knowledge and subjectivity in curriculum inquiry: Insights from Chen Kuan-Hsing's "Asia as Method". Curriculum Inquiry, 42, 153-178. doi: https://doi.org/10.1111/j.1467-873X.2011.00571.x

Massey, D. (1993). Power-geometry and a progressive sense of place. In J. Bird, B. Curtis, G. Robertson, \& L. Tricker (Eds.), Mapping the futures: Local culture, global change (pp. 59-69). London: Routledge.

Meusburger, P. (2015). Education, geography of. In J. D. Wright (Ed.), International encyclopedia of the social \& behavioral sciences (2nd ed., pp. 165-171). Amsterdam: Elsevier.

Nguyen, T. (2013). Selling western dreams: Australian transnational education in Vietnam and the formation of student identities. Australia: Monash University.

OECD (Organisation for Economic Co-operation and Development) (2014). Education at a glance 2014: Highlights. Paris: OECD. doi:10.1787/eag_highlights-2014-en

Project Atlas: Trends and Global Data 2014. Retrieved from https://www.iie.org/Research-andInsights/Project-Atlas.

Rizvi, F. (2012). Engaging with the Asian century. ACCESS: Critical Perspectives on Communication, Cultural \& Policy Studies, 31, 73-79.

Roshid, M. M., Siddique, M. N. A., Sarkar, M., Mojumder, F. A., \& Begum, H. A. (2015). Doing educational research in Bangladesh: Challenges in applying Western research methodology. In H. Zhang, P. Wing Keung Chan, \& J. Kenway (Eds.), Asia as method in education studies: A defiant research imagination (pp. 129-143). Abingdon: Routledge.

Sassen, S. (1998). Globalization and its discontents: Essays on the new mobility of people and money. New York: The New Press. 
Takayama, K. (2016). Deploying the post-colonial predicaments of researching on/with 'Asia' in education: A standpoint from a rich peripheral country. Discourse: Studies in the Cultural Politics of Education, 37, 70-88.

UNESCO, Institute of Statistics (2015). Global flow of tertiary-level students (interactive map). Retrieved from http://www.uis.unesco.org/EDUCATION/Pages/international-student-flow-viz. aspx

Universities Australia (2014, June 16). International links data. In Global engagement. Retrieved from Offshore Programs and International Links https://www.universitiesaustralia.edu.au/ global-engagement

Williams, R. (1977). Marxism and literature. Oxford, UK: Oxford University Press.

Zhang, H., Wing Keung Chan, P., \& Kenway, J. (Eds.). (2015). Asia as method in education studies: Towards a defiant research imagination. Abingdon: Routledge.

Open Access This chapter is licensed under the terms of the Creative Commons Attribution 4.0 International License (http://creativecommons.org/licenses/by/4.0/), which permits use, sharing, adaptation, distribution and reproduction in any medium or format, as long as you give appropriate credit to the original author(s) and the source, provide a link to the Creative Commons license and indicate if changes were made.

The images or other third party material in this chapter are included in the chapter's Creative Commons license, unless indicated otherwise in a credit line to the material. If material is not included in the chapter's Creative Commons license and your intended use is not permitted by statutory regulation or exceeds the permitted use, you will need to obtain permission directly from the copyright holder. 